УДК $821.161 .1-1$

DOI $10.17223 / 23062061 / 9 / 3$

\title{
А.Ф. Нургалиева
}

\section{ВОСПРИЯТИЕ ПОЭТИЧЕСКОГО ТЕКСТА ПОЭТОМ (М.И. ЦВЕТАЕВОЙ)}

\begin{abstract}
В статье намечаются закономерности прочтения поэтического текста Райнера Мария Рильке поэтом М.И. Цветаевой. Автор исследует коммуникацию как источник для понимания поэтических стратегий М.И. Цветаевой. Рассматриваются специфика обращения с «чужим» словом и особенности самораскрытия художественного мира через диалог с поэтом. На примере переписки анализируется взаимосвязь поэтики творчества М.И. Цветаевой и её отзывов о творчестве Р.М. Рильке. Ставится вопрос о диалектическом, философском характере лирики М.И. Цветаевой.

Ключевые слова: поэзия М.И. Цветаевой, восприятие поэзии, Р.М. Рильке, диалог.
\end{abstract}

$\mathrm{O}$

тношения читателя и автора всегда индивидуальны. Ключевым моментом в формировании роли читателя становится желание или нежелание воспринимающего вступить в диалог с чужим текстом. В творческое наследие М.И. Цветаевой входят посвященные поэтам лирика и эссе, а также письма. Адресатами поэтического и прозаического слова становятся А.А. Ахматова, В.Я. Брюсов, Вяч. Иванов, А.А. Блок, В.В. Маяковский, М.А. Волошин, Б.Л. Пастернак, К.Д. Бальмонт, О.Э. Мандельштам, Н.П. Гронский, А.С. Пушкин, Дж. Байрон, И. Гете, Г. Гейне, Р. Рильке.

Специфика диалога заключаются в том, что чужая поэзия является для поэта Цветаевой не материалом, к которому может быть найден некий «подход», а автор - не героем, который имеет некоторый биографический контекст. Вместе они становятся для поэта, по выражению Бахтина, «принципом», способом быть. В диалоге с творчеством Райнер Мария Рильке М.И. Цветаева, называя это явление, используют слово «сущность».

«Статья о Рильке потому еще бесполезна, - пишет М.И. Цветаева, - что он статей о других не писал, а о себе не читал. Не прочел бы (не прочтет) и моей. Рильке и статья (в Германии о нем даже пишут диссертации) - дикость. Вскрыть сущность нельзя, подходя со стороны. Сущность вскрывается только сущностью, изнутри внутрь, - не исследование, а проникновение. Взаимопроникнове- 
ние». Дальше Цветаева использует образ реки. «Дать вещи проникнуть в себя и - тем - проникнуть в нее. Как река вливается в реку. Точка слияния вод - но оно никогда не бывает точкой, посему: встреча вод - встреча без расставанья, ибо Рейн - Майн принял в себя, как Майн - Рейн. И только Майн о Рейне правду и знает (свою, майнскую, как Мозель - мозельскую, вообще-Рейна, - вообщеРильке - нам знать не дано). Как рука в руке, да, но еще больше: как река в реке. Проникаясь, проникаю. Всякий подход - отход» [1].

Переведя эти слова на научный язык, можем сказать, что лирический герой становится субъектом сознания самого поэта. Лирический герой Рильке входит в художественный мир М.И. Цветаевой и в нем трансформируется. Это подтверждается и тем, как автор отзывается о субъекте. Он наделяет художественный мир другого поэта такими характеристиками, которые мы могли бы отнести к его собственному.

После прочтения «Дуинских элегий» (1923) М.И. Цветаева не размышляет о звучании стиха, о его музыкальности, ритмичности, образности. Художественный мир Рильке растворился в ее поэтическом сознании и стал основой для трансляции собственных смыслов. Читатель становится автором:

«Тот свет (не церковно, скорее географически) ты знаешь лучше, чем этот, - пишет М.И. Цветаева, - ты знаешь его топографически, со всеми горами, островами и замками. Топография души - вот, что ты такое. И твоей книгой (ах, это была не книга - это стало книгой!) о бедности, паломничестве и смерти ты сделал для Бога больше, чем все философы и проповедники вместе (12-го мая 1926 г.)» [2].

Поэзия Рильке становится отражающим зеркалом для поэта М.И. Цветаевой, и ее поэзию тоже можно назвать «топографией души». «Поэтические “ситуации”, - пишет О.Г. Ревзина о поэзии М.И. Цветаевой, - не сюжетны, не событийны, а связаны с душевным прозрением, с мышлением о мире на поэтическом языке» [3]. Не случайно свой первый сборник «Вечерний альбом» Цветаева называет лирическим дневником. А на примере «Попытки комнаты» (1926), или «Поэмы воздуха» (1927), или «Поэмы Горы» $(1924,1939)$ мы видим, что художественное пространство уступает личностному переживанию, которое симультанно, которое не вспоминается, а переживается в данный момент, суть которого, по мнению Б.М. Гаспарова, может и остаться вне образов, так как поэт еще сам его не зна- 
ет: он сначала его записывает, а затем уже в написанном узнает [4]. Но записывает его как реальность души, как реальность духовную, поэтому Священная история становится одним из источников образов лирики поэта, а глагол «быть» получает особый статус. Быть значит отражать суть. Об этом, в частности, пишет исследователь лингвистического аспекта поэзии М.И. Цветаевой Л.В. Зубова [5].

Вслушивание поэта в свой душевный мир и фиксирование его через детали внешнего, осязаемого, имеющего устойчивые оценки, исследователями принято называть мифологизацией. Но, как уже было сказано, впечатление в произведениях М.И. Цветаевой не замещает мысль, как в творчестве импрессионистов, здесь впечатление трансформируется в осознание.

Осознание, выросшее в союзе с другим поэтом, читатель Цветаева доносит в письме до поэта Рильке, т.е. снова вступает в диалог, на что получает ответ надписью на «Дуинских элегиях» (1923): «Марине Ивановне Цветаевой. Касаемся друг друга. Чем? Крылами. // Издалека ведем свое родство. // Поэт один. И тот, кто нес его, // Встречается с несущим временами. Райнер Мария Рильке. (Валь Мон, Глион, Кантон Во, Швейцария, в мае 1926)» [6].

Диалог с субъектом своего сознания выводит поэта к задачам философа и дает возможность продолжения диалога на другом уровне. Сознание поэта становится предметом для собственных интенций и интенций читательских, художественный мир разомкнут, так же как разомкнута читательская позиция.

«Поэт - тот, кто преодолевает (должен преодолеть) жизнь», пишет М.И. Цветаева Рильке». «Вы возвращаете словам их изначальный смысл, вещам же - их изначальные слова (ценности). Вы говорите “великолепно", Вы говорите о “великой лепоте”, о значении слова при его возникновении. (Теперь же “великолепно” - всего лишь стершийся восклицательный знак)» [6].

Каким образом эта характеристика может относиться к самой Цветаевой? Её лирика легко прочитывается в постклассической эстетике благодаря сталкиванию логически не связанных образов, на основе которых, казалось бы, невозможно построить повествование.

Истоки этого приема лежат в романтической эстетике. Поэтом создается поэтическое пространство, где органично могло бы развернуться «неизъяснимое» путем выстраивания семантических рядов через этимологическое значение слова. Таким образом, в глуби- 
не между художественными образами лежит связь, разгадать ее как некий шифр, ребус предоставляется другому сознанию, и лирика М.И. Цветаевой также является заданностью для восприятия другого. Готовность стать субъектом другого сознания позволяет быть читателем, проникающим в мир другого поэта. Границы художественного мира воспринимающего и воспринимаемого становятся прозрачными.

«Дорогой Райнер, - пишет. М.И. Цветаева, - у Гёте где-то сказано, что на чужом языке нельзя создать ничего значительного, - я же всегда считала, что это неверно. (Гёте никогда не ошибается в целом, он прав в итоговом смысле, поэтому сейчас я несправедлива к нему). Поэзия - уже перевод, с родного языка на чужой - будь то французский или немецкий - неважно. Для поэта нет родного языка. Писать стихи и значит перелагать» [6].

Мы же скажем, что читать стихи другого для М.И. Цветаевой это значит перелагать чужой художественный мир на свой родной язык.

\section{Лumepamypa}

1. «Несколько писем Райнер Мария Рильке». http://www.tsvetayeva.com/ prose/ pr_rayner_nesk.php

2. Письма Р.М. Рильке. http://www.tsvetayeva.com/letters/let_rajner_7.php

3. Ревзина О.Г. Собственные имена в поэтическом идиолекте М. Цветаевой. Состав собственных имен. http://danefae.org/lib/ogrevzina/

4. Гаспаров Б.М. Язык, память, образ. Лингвистика языкового существования. http://www.gumer. info/bibliotek_Buks/Linguist/Gasp/16.php

5. Зубова Л.В. Поэзия Марины Цветаевой: Лингвистический аспект. Л.: Изд-во Ленингр. ун-та, 1989. 264 с.

6. http://www.tsvetayeva.com/letters/let_rajner_7.php

\section{POETIC TEXT PERCEPTION BY POET MARINA TSVETAEVA.}

Text. Book. Publishing, 2015, 2 (9), pp. 39-43. DOI: 10.17223/23062061/9/3

Nurgalieva Anastasiya F. Tomsk State University Research Library (Tomsk, Russian Federation). E-mail: virtr@lib.tsu.ru

Keywords: poetry of M. Tsvetaeva; perception of poetry; R.M. Rilke; dialogue.

The relationship of the reader and the author is always individual. The role of the reader always assumes the importance of one's willingness or unwillingness to engage in a dialogue with someone else's text. Marina Tsvetaeva's legacy contains materials that allow speaking about her dialogue with an "alien" text, in particular, with that of Rilke. The feature of this dialogue is that alien poetry and alien authors for Tsvetaeva are the "principle" (M. Bakhtin), a way of being, the "essence" (M. Tsvetaeva). 
Tsvetaeva's comment on an article about Rilke suggests that this essence of "is only revealed by essence", through interpenetration. The lyrical hero of the "alien" author, Rilke, becomes the subject of Tsvetaeva's consciousness; Rilke's art world dissolves in Tsvetaeva's mind and is perceived through the art world of her own. The art world of the "alien" poet becomes the basis for the translation of her own senses.

Reflection of Rilke's poetry in the poetry of Tsvetaeva endows the latter with philosophical, intimate lyrical and spiritual features; makes it a poetry of impressions. Tsvetaeva's dialogue with Rilke, the subject of her consciousness, makes her philosophical poetry.

After the penetration into the position of a different person, one can unravel the artistic images of the poet. Readiness to become a subject of another consciousness allows becoming a reader penetrating into the world of another poet. Such penetration is particularly possible in poetry. For Tsvetaeva, reading poetry of a different author means to interpret someone else's art world into her mother tongue.

\section{References}

1. Tsvetaeva, M. (n.d.) Neskol'ko pisem Rayner Mariya Ril'ke [Several letters to Rainer Maria Rilke]. [Online] Available from: http:/www.tsvetayeva. com/ prose/ pr_rayner_nesk.php

2. Tsvetaeva, M. (n.d.) Pis'ma R.M. Ril'ke [Letters to R.M. Rilke]. [Online] Available from: http://www.tsvetayeva.com/letters/let_rajner_7.php.

3. Revzina, O.G. (1991) Sobstvennye imena v poeticheskom idiolekte M. Tsvetaevoy [Proper names in the poetic idiolect of Marina Tsvetaeva]. In: Grigoriev, V.P. (ed.) Poetika i stilistika 1988-1990 [Poetry and Stylistics. 1988-1990]. Moscow: Nauka. pp. 172-192.

4. Gasparov, B.M. (1996) Yazyk, pamyat', obraz. Lingvistika yazykovogo sushchestvovaniya [Language, Memory, Image. Linguistics of Language Existence]. Moscow: Novoe literaturnoe obozrenie. [Online] Available from: http://www.gumer. info/ bibliotek_Buks/ Linguist/Gasp/16.php

5. Zubova, L.V. (1989) Poeziya Mariny Tsvetaevoy: Lingvisticheskiy aspect [The Poetry of Marina Tsvetaeva: Linguistic Aspect]. Leningrad: Leningrad State University.

6. Tsvetaeva, M. (n.d.) Pis'ma R.M. Ril'ke [Letters to R.M. Rilke]. [Online] Available from: http://www.tsvetayeva.com/letters/let_rajner_7.php. 